\title{
Generating optimal features to find out potent molecules against dengue virus: pharmacophore and QSAR approaches
}

\author{
Kazi Amirul Hossain (kaziamirulhossain@gmail.com) ${ }^{a}$ \\ ${ }^{a}$ Department of molecular modeling, Dr. Reddy's Institute of Life Sciences, Hyderabad-500046, India
}

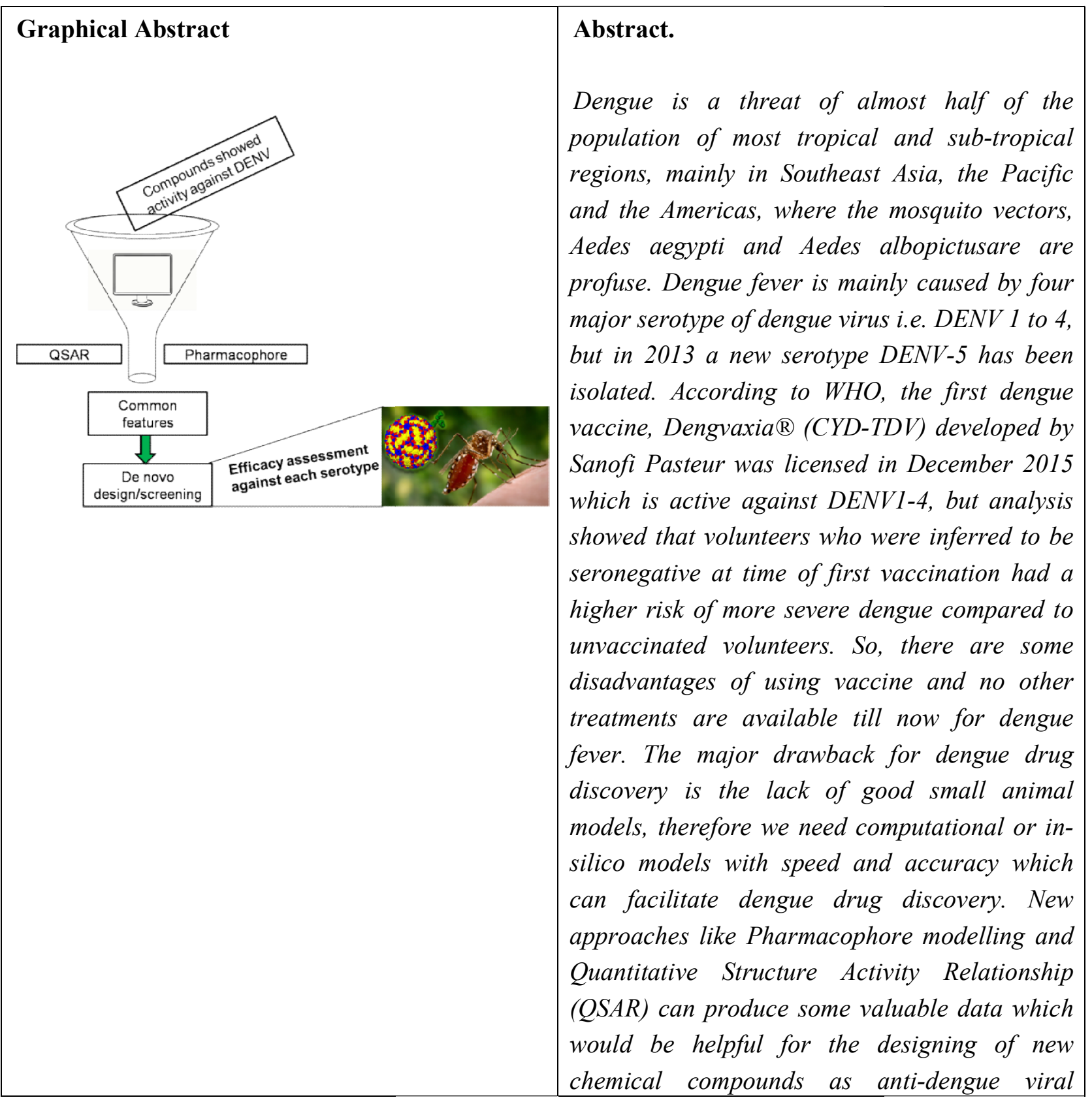




\begin{tabular}{|l|l|}
\hline & $\begin{array}{l}\text { drug(s). Few evaluations of natural products as } \\
\text { well as synthesised chemicals against different } \\
\text { proteins of DENV have been published. In this } \\
\text { present study, I have collated the entire } \\
\text { molecule tested against DENV, and generating } \\
\text { common ligand based pharmacophoric features } \\
\text { from them, which could be helpful for the de } \\
\text { novo synthesis and screening of compounds } \\
\text { from databases against DENV. In addition, I am } \\
\text { trying to develop 2D-QSAR models (using both } \\
\text { congeneric series like different derivatives of } \alpha- \\
\text { ketoamides as well as non-congeneric series of } \\
\text { molecules who's biological activities are } \\
\text { reported) to get some easily interpretable } \\
\text { descriptors responsible for the activity. Finally, } \\
\text { the generated hits will be undergoing for ADME } \\
\text { analysis to investigate their drug-likeness } \\
\text { properties followed by molecular docking and } \\
\text { MD simulation to see their affinity against } \\
\text { different proteins of DENV. }\end{array}$ \\
\hline
\end{tabular}

\section{References}

1. Mustafa, M. S., V. Rasotgi, S. Jain, and Vl Gupta. "Discovery of fifth serotype of dengue virus (DENV-5): A new public health dilemma in dengue control." Medical Journal Armed Forces India 71, no. 1 (2015): 67-70.

2. Steuer, Christian, Christian Gege, Wolfgang Fischl, Karl H. Heinonen, Ralf Bartenschlager, and Christian D. Klein. "Synthesis and biological evaluation of $\alpha$-ketoamides as inhibitors of the Dengue virus protease with antiviral activity in cell-culture." Bioorganic \& medicinal chemistry 19, no. 13 (2011): 4067-4074. 